\title{
Misdiagnosis of Patients with Cervicogenic Headache: A Case Series Study
}

\author{
Mohammad Amir Bonakdar Tehrani ${ }^{1}$, Mohammad Akbari² ${ }^{2 *}$ Mehdi Dadgoo $^{3}$
}

1. MSc. Student, Department of Physiotherapy, Iran University of Medical Sciences, Tehran, Iran

2. Professor, Department of Physiotherapy, Iran University of Medical Sciences, Tehran, Iran

3. Assistant Professor, Department of Physiotherapy, Iran University of Medical Sciences, Tehran, Iran

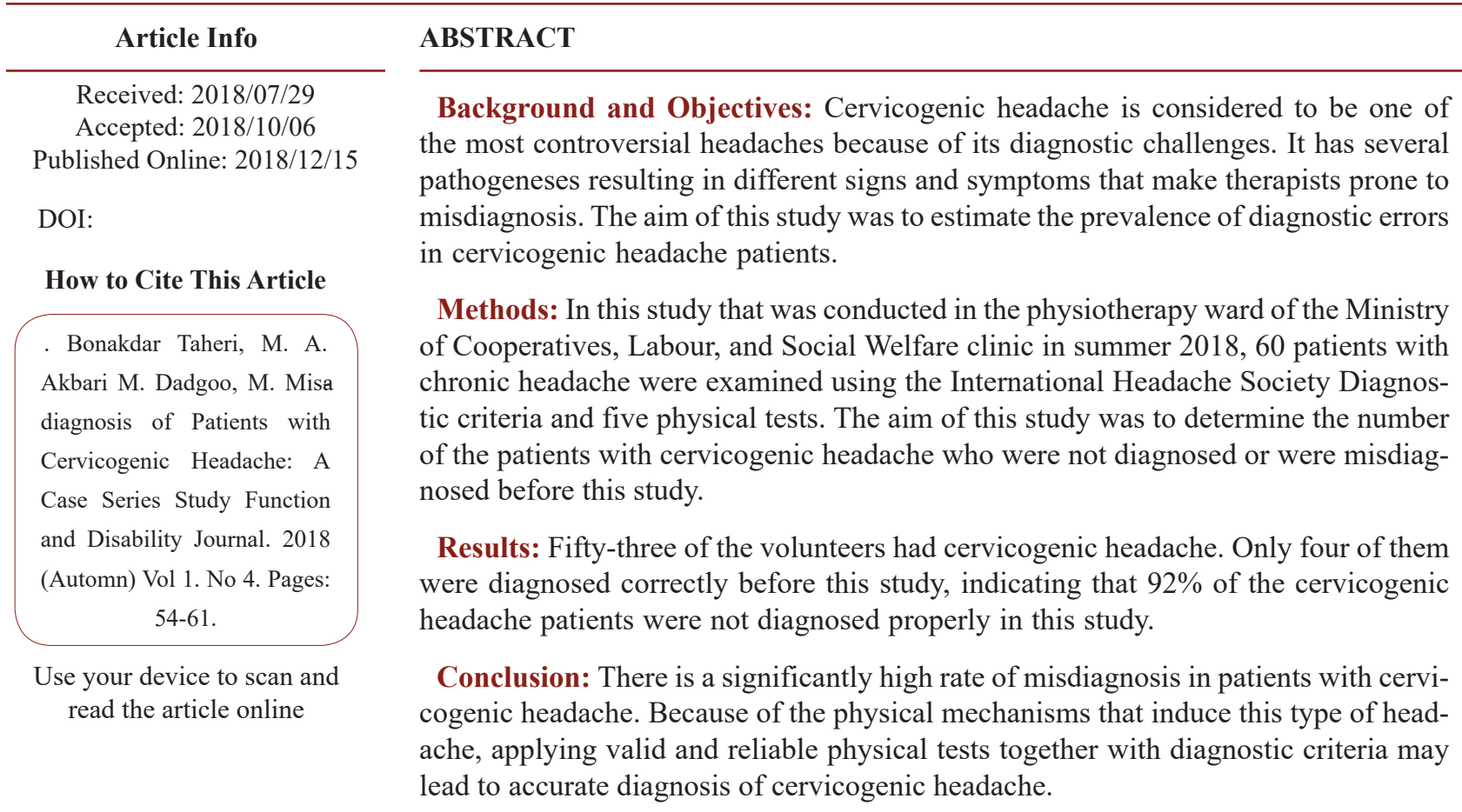

Keywords: Cervicogenic headache, Misdiagnosis, Diagnostic error

Corresponding Information:

Mohammad Akbari, Professor, Department of Physiotherapy, Iran University of Medical Sciences, Tehran,

Iran Email: akbari.mo@iums.ac.ir Tel: +982122227124

Copyright (C) 2018, Function and Disability This is an original open-access article distributed under the terms of the Creative Commons Attribution-noncommercial 4.0 International License which permits copy and redistribution of the material just in noncommercial usages with proper citation.

\section{Introduction}

Cervicogenic headache is the most controversial headache (Sjaastad, 1992). According to the most recent International Headache Societies description, this type of headache is caused by a disorder of the cervical spine and its components including bony, disc and/or soft tissue elements. It is usually but not invariably accompanied by neck pain (IHS, 2013).

A review of the literature suggests the following mechanisms; One of the main mechanisms is the interference of the sensory inputs of the trigeminal nerve with the sensory signals of the first 3 cervical nerve roots in the trigeminal nucleus caudalis (Bogduk \& Govind, 2009). Some other mechanisms have been less addressed. Anatomical studies have shown an attachment of the suboccipital tissue to the dura mater at the craniocervical junction. This suggests a role for the dura as a nociceptive structure in cervicogenic headache (Haldeman \& Dagenais, 2001). Some studies have shown that trigger points of the sternocleidomastoid muscle are one of the important causes of this type of headache. Beside overactivation of the SCM, activity of longus colli and other deep flexors of the head are 
reduced, resulting in motor control impairment (Amiri, Jull, Bullock-Saxton, Darnell, \& Lander, 2007; Roth, Roth, Weintraub, \& Simons, 2007). Myofascial restrictions and muscles trigger points are another etiology of cervicogenic headache (Fernandez-De-Las-Penas \& Cuadrado, 2016). Tempromanibular joint dysfunction is another cause of this type of headache (Fernandez-De-Las-Penas, 2010; Fernandez-de-las-Penas \& Cuadrado, 2014).

As also reported by Haldeman et al., one of the most controversial areas in cervicogenic headache is the discussion of its causes (Haldeman \& Dagenais, 2001). Cervicogenic headache is the most controversial headache because of the difficulties in accurate diagnosis (Sjaastad, 1992).

In 1990, Pfaffenraph et al. reported that $50 \%$ of the patients with cervicogenic headache were misdiagnosed (Pfaffenrath \& Kaube, 1990). Moreover, Bono et al. suggested that most of the patients with cervicogenic headache fulfilled $75 \%$ of the diagnostic criteria of migraine headache (Bono, Antonaci, Ghirmai, Sandrini, \& Nappi, 1998). In addition, a case report study reported four patients with cervicogenic headache whose problem was missed and suffered from headache for almost 16 years.

Sjaastad introduced cervicogenic headache as a real headache and described the overlapping of signs and symptoms of 3 types of headaches (Antonaci \& Sjaastad, 2011). It is clear that relying on signs and symptoms of cervicogenic headache may not lead therapists to a correct diagnosis. Some features help to distinguish cervicogenic headache from other types of headache, including side lock pain and provocation by head movement and digital pressure on the neck muscle resulting in posterior-to-anterior radiation of pain (ICHD 3beta). Although these symptoms are some of the characteristics of cervicogenic headache but they are not unique to it. In 1999, Suijlekom et al. conducted an interobserver study to evaluate the reliability of the diagnostic criteria of cervicogenic headache. They used the kappa index to assess the reliability. The following criteria achieved a high kappa score for accurate diagnosis of cervicogenic headache (van Suijlekom, de Vet, van den Berg, \& Weber, 1999) (Table 1).

Table 1. Reliability of cervicogenic headache diagnostic criteria

\begin{tabular}{|ccc|}
\hline Diagnostic criteria & Kappa score for reliability & Level of evidence \\
\hline Radiate to ipsilateral shoulder & $0 / 76$ & High \\
\hline Pain start in the neck & $0 / 67$ & High \\
\hline Restrict range of motion & $0 / 54$ & Moderate \\
\hline Provocation by neck movement & $0 / 45$ & Moderate \\
\hline
\end{tabular}

Other features or old criteria have a high kappa score as well, but they are no longer included in the ICHD-3. According to Bono et al., focusing on diagnostic criteria as a solitary way for diagnosis may increase the risk of diagnostic error to $75 \%$. Utilizing physical examination alongside diagnostic criteria, can lead to an accurate diagnosis (Hall \& Robinson, 2004).

Suijlekom et al. assessed the reliability of some physical examinations in 2000. Among the assessed tests, the sternocleidomastoid and mastoid pressure pain tests were reported to be the most reliable ones (Hans A. van Suijlekom \& Wilhelm E.J. Weber, 2000).
It was recommended that integration of the articular, muscular, and neural systems into evaluation may result in a more accurate diagnosis (CÉSAR FERNÁNDEZDE-LAS-PEÑAS, 2009). To do this study, the reliable tests for diagnosis of cervicogenic headache were extracted from one of the most updated systematic review studies (Rubio-Ochoa et al., 2016) (Table 2).

In spite of the fact that lack of a golden standard for diagnosis of cervicogenic headache confuses the therapists and increases diagnostic error, utilizing valid diagnostic criteria together with reliabe physical examinations will decrease the rate of error. 
In this study, 4 diagnostic crtieria and 5 physical tests introduced earlier were used as reliable tools for accurate diagnosis. The objective of this study was to evaluate misdagnosis or diagnostic error prevalnece in patients with cervicogenic headache.

Table 2. Physical test for cervicogenic headache diagnosis

\begin{tabular}{|c|c|c|c|c|}
\hline Tests & Study & Kappa Score & $\begin{array}{l}\text { Sensitivity/ } \\
\text { Specificity }\end{array}$ & Level of evidence \\
\hline Flexion-Rotation & Hall et al. 2008 & $0 / 85$ & $\begin{array}{l}90 \% \\
85 \%\end{array}$ & High \\
\hline $\begin{array}{l}\text { Passive accessory } \\
\text { intervertebral movement }\end{array}$ & Zito et al. 2006 & - & $\begin{array}{l}\mathrm{C} 0-\mathrm{C} 1: 59 / 82 \% \\
\mathrm{C} 1-\mathrm{C} 2: 62 / 87 \% \\
\mathrm{C} 2-\mathrm{C} 3: 65 / 78 \%\end{array}$ & $\begin{array}{l}\text { Moderate } \\
\text { to high }\end{array}$ \\
\hline Craniocervical flexion test & Zito et al. 2006 & - & - & Low \\
\hline FRT, PAIM, CCFT & Jull et al. 2007 & - & $\begin{array}{l}100 \% \\
94.4 \%\end{array}$ & High \\
\hline
\end{tabular}

\section{Materials and Methods}

The protocol of this case series was approved by the Ethics Committee of Iran University of Medical Sciences (IR.IUMS.REC.1397.179). In this study, the rate of cervicogenic headache misdiagnosis was evaluated in patients with chronic headache. Sixty patients with chronic headache entered the study after applying the inclusion criteria. Informed consent was obtained from all participants. The subjects were then examined by the researcher. The following checklist was completed for them (Table 3).

Table 3. Examination items for diagnosis of patients with cervicogenic headache

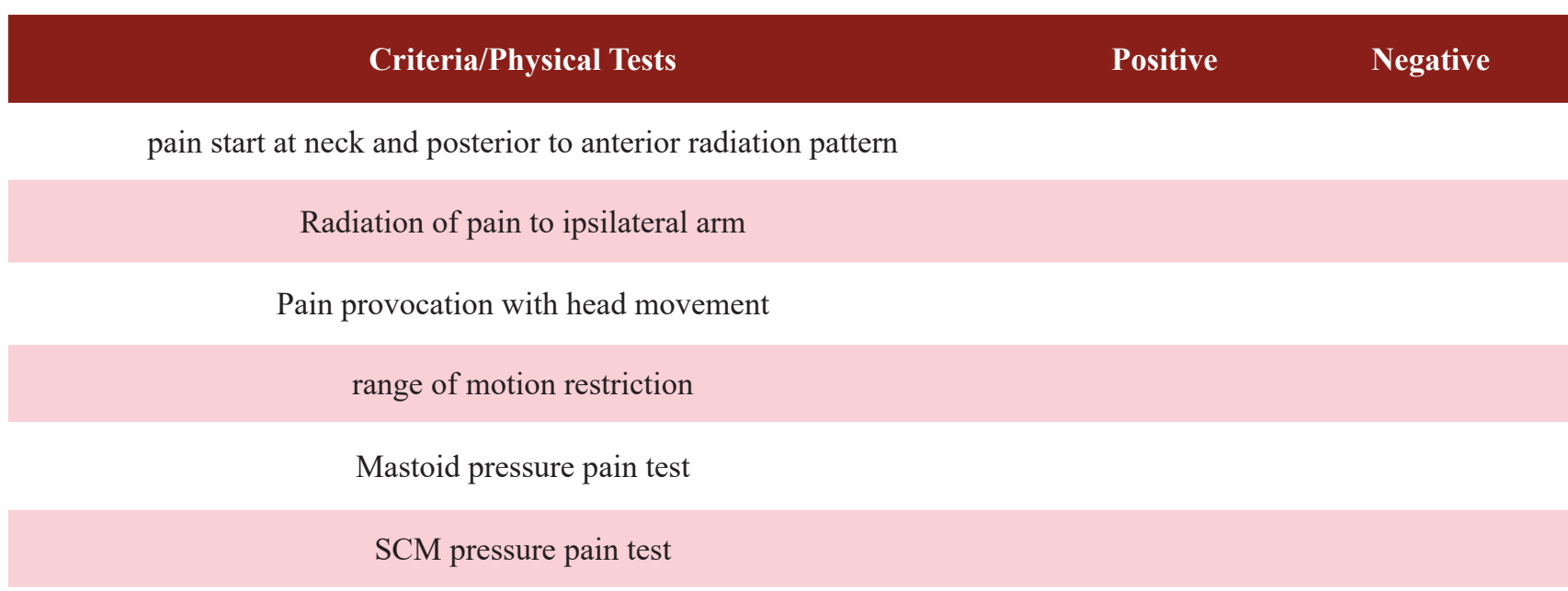

Flexion rotation test

Craniocervical flexion test

Passive accessory intervertebral movement test 
The inclusion criteria were: 1- A history of headache for at least one year; 2- History of at least one neurologist visit for headache; 3- Male/Female gender; 4- Age 18-55 years; 5 - No rheumatic disease with deformity in the acute phase; 6- No acute fracture in the cervical or upper thoracic spine and no old fracture with deformity; 7- lack of instability in the upper cervical spine; 8- Negative history of brain injury; 9- lack of hypertension; 10- negative history of certain diseases such as cancer, hemophilia, psychiatric problems, and uncontrolled diabetes.

The diagnsotic criteria were assessed in an interview and the following tests were done:

- Flexion rotation test: The subject layed supine on the examination table and was asked to relax while his/her neck was moved to the end range of cervical flexion by the examiner. In this flexed position, the head and neck was passively rotated as far as possible whitin comfortable limits. Any signs of asymmetry, restriction, and pain provocation was noted (Hall \& Robinson, 2004).

- Craniocervical flexion test: With the patient in the supine postion, the examiner examined both SCM through palpation and observation. In the meantime, the patient was asked to nod or flex his/her head on the neck. Any signs of SCM contraction was recorded
(Fernandez-de-las-Penas \& Cuadrado, 2014).

- Passive accessory intervertebral movement test: The examiner palpated the spinous process of the cervical spine starting at $\mathrm{C} 2$ to $\mathrm{C} 7$. Moreover, the transverse process of $\mathrm{C} 1$ to $\mathrm{C} 7$ was checked. Pressure was applied slowly and the quality of movement, end feel, and asymmetry was noted (Magee, 2014).

Some physical tests are more subjective than others are, such as mastoid and SCM pressure pain tests, and the risk of bias may affect the results. So physical tests were done twice by the researcher and the co-researcher; then, the results were compared and intra correlation coefficient was analyzed. The software SPSS 20 (SPSS Inc. Chicago, Ill., USA) was used for data analysis. The Shapiro-Wilk test was used for examining the data distribution. This study was done in the physiotherapy ward of the Ministry of Cooperatives, Labour, and Social Welfare clinic in summer 2018.

\section{Results}

The mean age of the participants was $42.55 \pm 7.85$ year. Forty-eight subjects were female and 12 were male. They suffered from headache for a mean duration of $13.95 \pm 9.76$ years and visited the neurologist for $4.73 \pm 4.16$ times during this period. Table 4 presents some clinical features of the subjects.

Table 4. Some clinical features of volunteers

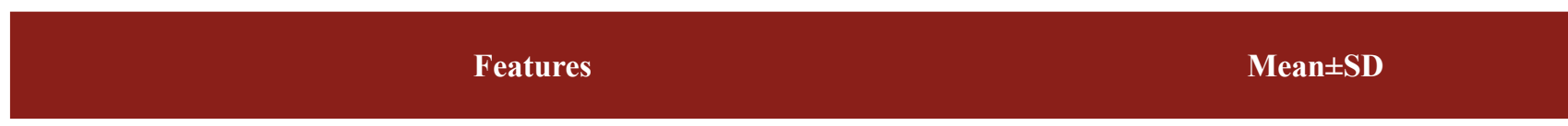

Work lost days

$2 / 93 \pm 3 / 36$

Frequency of headache (days)

Intensity of headache (0-25 VAS chart)
$6 / 20 \pm 5 / 99$

$18 / 20 \pm 3 / 99$
Duration of headache (hours)

One of the most important questions was the previous diagnosis of the headache. The following pie diagram shows the variety of previous diagnoses by neurologists (Figure 1).

According to Figure 1, the majority of the headaches were diagnosed as a migraine headache. After exami- nation, the following table was achieved about the results of the tests. The tests were done twice for 10 patients and the results were compared. There was no significant difference in the results and there was no controversy in the diagnosis (Figure 2). 


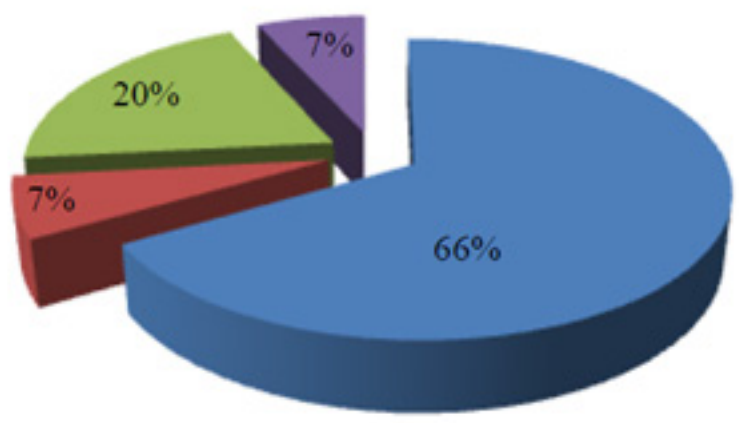

= Migraine

- Tension type

= Othere types

a Cervicogenic headache

Figure 1. Prevalence of previous diagnosis for the volunteers

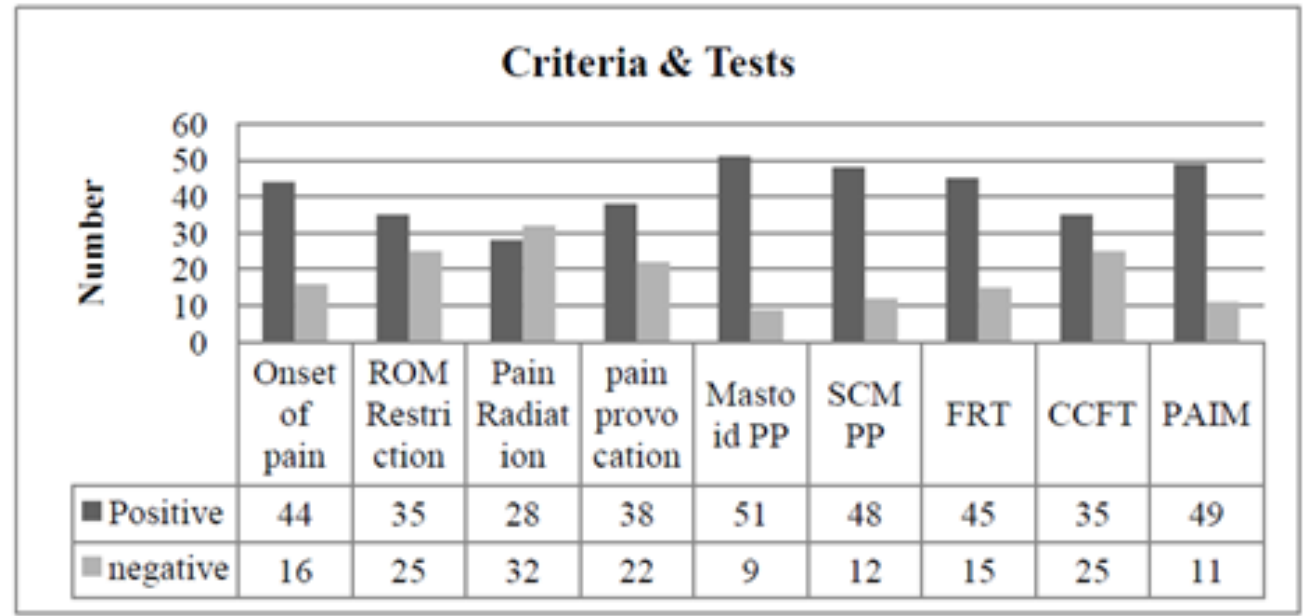

Figure 2. Brief reporting of test's results

Sixty volunteers were examined in this study of whom 53 met at least two of the inclusion criteria and two of the physical tests, indicating a diagnosis of cervicogenic headache. However, only 4 of them were previously diagnosed with cervicogenic headache by neurologists. Therefore, 49 probably had cervicogenic headache that was not diagnosed previously, suggesting a high rate of misdiagnosis (92.45\%). All diagnostic criteria and tests were positive in 8 subjects that were all diagnosed with migraine headache by their neurologists. All diagnostic criteria were met in 10 subjects and all physical tests were positive in 20 patients. Seven participants had other types of headache (Figure 3).

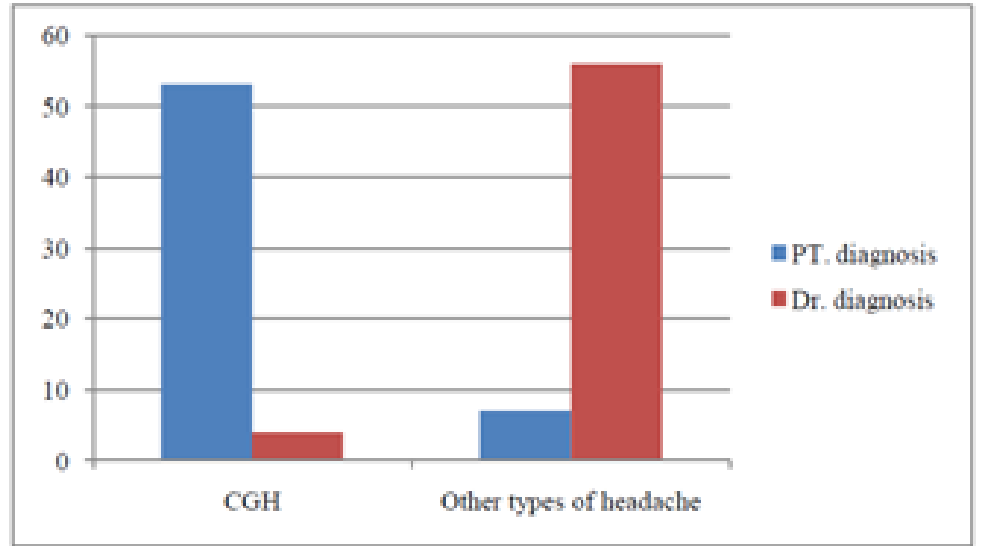

CGH: cervicogenic headache, PT: physiotherapy, Dr: doctor.

Figure 3. The comparison of prior and actual diagnosis 


\section{Discussion}

The main finding of this study was a very high rate of misdiagnosis of cervicogenic headache $(92.45 \%)$. Because of the lack of a golden standard for diagnosis of this type of headache, the most recent IHS diagnostic criteria and five recommended tests in the literature were used this study.

Different misdiagnosis rates for cervicogenic headache have been reported. Based on different population and diagnostic criteria, the rate of misdiagnosis varies from 50\% to 75\% (Pfaffenrath \& Kaube, 1990; Roth et al., 2007). There is a case report of four patients with cervicogenic headache who were missed. Their headaches were diagnosed as migraine by neurologists, but all of them had greater occipital neuralgia. Some of them had paraclinical data such as laboratory tests or imaging (CT scan, MRI, X-ray) (Xiaobin Yi, 2005). In this case report, only four cases were evaluated just by tinel sign test of greater occipital nerve. In this study, 60 patients with chronic cervicogenic headache were evaluated by four diagnostic criteria and five clinical tests. In other studies, diagnostic evaluation was only based on diagnostic criteria. In this study in addition to diagnostic criteria, reliable clinical tests were used.
As mentioned earlier, multiple mechanisms cause cervicogenic headache and each of them can produce specific signs and symptoms that may overlap with other types of headaches and confuse the physician.

\section{Conclusion}

Regardless of the high rate of cervicogenic headache misdiagnosis, there is a lack of reliable and valid methods for accurate diagnosis of this type of headache, which increases direct and indirect costs, work loss, and missed days and decreases the quality of life of the patients. Practitioner should not rely on signs and symptoms for diagnosis of cervicogenic headache. Moreover, most studies suggest that paraclinical findings may not lead to an accurate diagnosis. It seems that utilizing reliable physical tests along with standard diagnostic criteria can help therapists or neurologists to diagnose cervicogenic headache accurately.

\section{Acknowledgment}

The authors thank all those who helped them writing this paper.

\section{Conflict of Interest Statement}

The authors have no conflict of interest to declare.

\section{References}

A Clinical Perspective. THE JOURNAL OF MANUAL \& MANIPULATIVE THERAPY, 16(2), 1.

Amiri, M., Jull, G., Bullock-Saxton, J., Darnell, R., \& Lander, C. (2007). Cervical musculoskeletal impairment in frequent intermittent headache. Part 2: subjects with concurrent headache types. Cephalalgia, 27(8), 891-898.

Antonaci, F., \& Sjaastad, O. (2011). Cervicogenic headache: a real headache. Curr Neurol Neurosci Rep, 11(2), 149-155.

Bogduk, N., \& Govind, J. (2009). Cervicogenic headache: an assessment of the evidence on clinical diagnosis, invasive tests, and treatment. Lancet Neurol, 8(10), 959-968.

Bono, G., Antonaci, F., Ghirmai, S., Sandrini, G., \& Nappi, G. (1998). The clinical profile of cervicogenic headache as it emerges from a study based on the early diagnostic criteria (Sjaastad et al., 1990). Funct Neurol,
13(1), 75-77.

CÉSAR FERNÁNDEZ-DE-LAS-PEÑAS, P., DO, PhD , Department of Physical Therapy, Universidad Rey Juan Carlos, Madrid, Spain. (2009). Clinical Evaluation of Cervicogenic Headache:

Fernandez-De-Las-Penas, C. (2010). Tension-Type and Cervicogenic Headache Sudbury, Massachusetts: JONES AND BARTLETT PUBLISHERS.

Fernandez-de-las-Penas, C., \& Cuadrado, M. L. (2014). Therapeutic options for cervicogenic headache. Expert Rev Neurother, 14(1), 39-49.

Fernandez-De-Las-Penas, C., \& Cuadrado, M. L. (2016). Dry needling for headaches presenting active trigger points. Expert Rev Neurother, 16(4), 365-366.

Haldeman, S., \& Dagenais, S. (2001). Cervicogenic headaches: a critical review. Spine J, 1(1), 31-46.

Hall, T., \& Robinson, K. (2004). The flexion-rotation test 
and active cervical mobility--a comparative measurement study in cervicogenic headache. Man Ther, 9(4), 197-202. Hans A. van Suijlekom, M. H. C. W. d. V., PhD; Suzanne G.M. van den Berg, MSc;, \& Wilhelm E.J. Weber, M., PhD. (2000). Interobserver Reliability in Physical Examination of the Cervical Spine in Patients With Headache. Headache, 40.

IHS. (2013). The International Classification of Headache disorders, 3rd edition, (beta version). Cephalalgia, 33(9).

Magee, D. J. (2014). ORTHOPEDIC PHYSICAL ASSESSMENT. Canada: Elsevier.

Pfaffenrath, V., \& Kaube, H. (1990). Diagnostics of cervicogenic headache. Funct Neurol, 5(2), 159-164.

Roth, J. K., Roth, R. S., Weintraub, J. R., \& Simons, D. G. (2007). Cervicogenic headache caused by myofascial trigger points in the sternocleidomastoid: a case report. Cephalalgia, 27(4), 375-380.
Rubio-Ochoa, J., Benitez-Martinez, J., Lluch, E., Santacruz-Zaragoza, S., Gomez-Contreras, P., \& Cook, C. E. (2016). Physical examination tests for screening and diagnosis of cervicogenic headache: A systematic review. Man Ther, 21, 35-40.

Sjaastad, O. (1992). Cervicogenic headache: the controversial headache. Clin Neurol Neurosurg, 94 Suppl, S147-149.

van Suijlekom, J. A., de Vet, H. C., van den Berg, S. G., \& Weber, W. E. (1999). Interobserver reliability of diagnostic criteria for cervicogenic headache. Cephalalgia, 19(9), 817-823.

Xiaobin Yi, A. J. C., Robin J, Hamill-ruth, and John C. Rowlingson. (2005). Cervicogenic Headache in Patients With Presumed Migraine: Missed Diagnosis or MisDiagnosis? American Pain Society, 6(10), 4. 


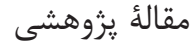

\section{تشخيص اشتباه بيماران مبتلا به سردرد سرويكوزنيك: مطالعله جند مورد \\ محمدامير بنكدار طهر انى'، محمد اكبرى "َ"، مهدى دادكوّ"}

$$
\begin{aligned}
& \text { 1. دانشجوى كارشناسى ارشد، كروه فيزيوترايى، دانشكاه علوميزشكى ايران، تهران، ايران }
\end{aligned}
$$

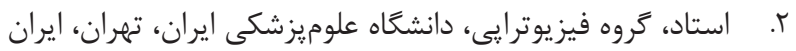

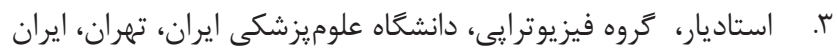

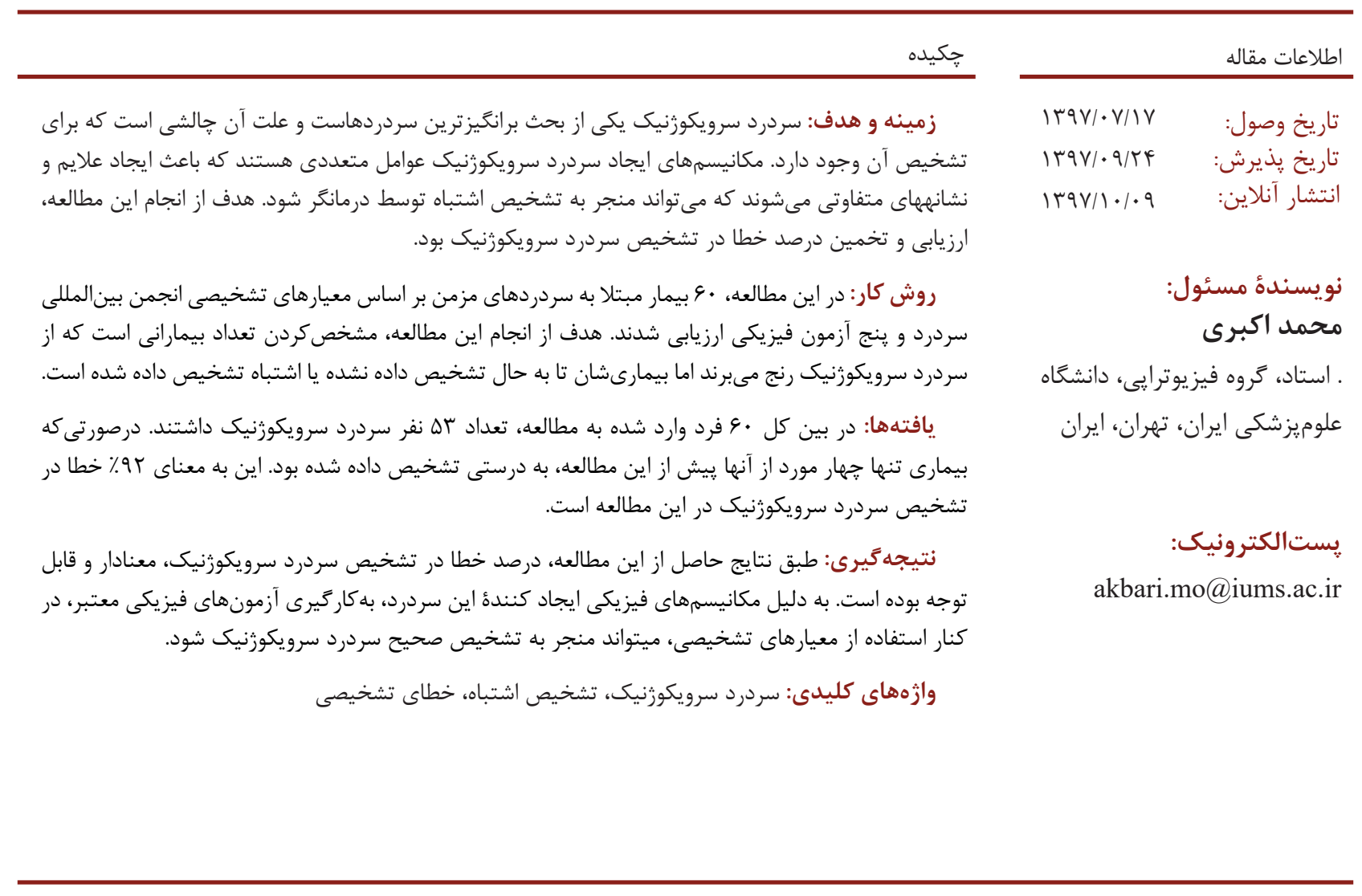

